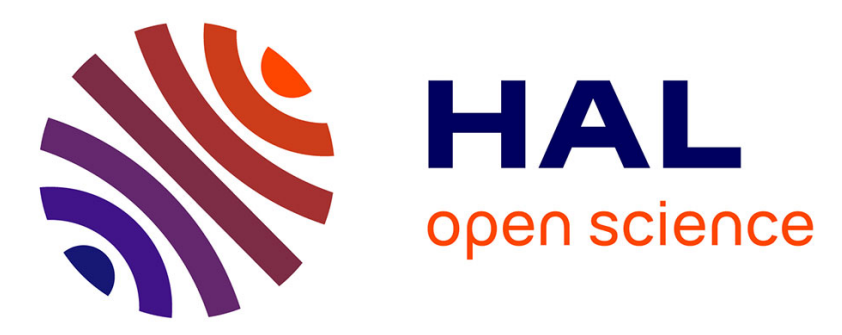

\title{
Engineering E. coli for magnetic control and the spatial localization of functions
}

\author{
Mary Aubry, Wei-An Wang, Yohan Guyodo, Eugénia Delacou, Jean-Michel \\ Guignier, Olivier Espeli, Alice Lebreton, François Guyot, Zoher Gueroui
}

\section{- To cite this version:}

Mary Aubry, Wei-An Wang, Yohan Guyodo, Eugénia Delacou, Jean-Michel Guignier, et al.. Engineering E. coli for magnetic control and the spatial localization of functions. ACS Synthetic Biology, 2020, 10.1021/acssynbio.0c00286 . hal-03038795

\section{HAL Id: hal-03038795 https://hal.science/hal-03038795}

Submitted on 3 Dec 2020

HAL is a multi-disciplinary open access archive for the deposit and dissemination of scientific research documents, whether they are published or not. The documents may come from teaching and research institutions in France or abroad, or from public or private research centers.
L'archive ouverte pluridisciplinaire HAL, est destinée au dépôt et à la diffusion de documents scientifiques de niveau recherche, publiés ou non, émanant des établissements d'enseignement et de recherche français ou étrangers, des laboratoires publics ou privés. 


\section{Engineering $E$. coli for magnetic control and the spatial localization of functions}

Mary Aubry ${ }^{1}$, Wei-An Wang ${ }^{1,2}$, Yohan Guyodo ${ }^{3}$, Eugénia Delacou ${ }^{1}$, Jean-Michel Guignier ${ }^{2}$, Olivier Espeli ${ }^{4}$, Alice Lebreton ${ }^{5,6}$, François Guyot ${ }^{2,7}$, Zoher Gueroui ${ }^{{ }^{*}}$

${ }^{1}$ PASTEUR, Department of Chemistry, École Normale Supérieure, PSL University, Sorbonne Université, CNRS, 75005 Paris, France.

2 IMPMC, Muséum National d'Histoire Naturelle, Sorbonne Université, UMR CNRS 7590, 75005 Paris, France.

${ }^{3}$ Université de Paris, Institut de physique du globe de Paris, CNRS, F-75005 Paris, France.

${ }^{4}$ CIRB-Collège de France, CNRS-UMR724, INSERM U1050, PSL Research University, Paris, France.

${ }^{5}$ Institut de biologie de l'ENS (IBENS), Département de biologie, École normale supérieure, CNRS, INSERM, PSL University, 75005 Paris, France.

${ }^{6}$ INRAE, IBENS, 75005 Paris, France.

${ }^{7}$ Institut Universitaire de France (IUF).

*Corresponding author. Email: zoher.gueroui@ens.fr 


\begin{abstract}
The fast-developing field of synthetic biology enables broad applications of programmed microorganisms including the development of whole-cell biosensors, delivery vehicles for therapeutics, or diagnostic agents. However, the lack of spatial control required for localizing microbial functions could limit their use and induce their dilution leading to ineffective action or dissemination. To overcome this limitation, the integration of magnetic properties into living systems enables a contact-less and orthogonal method for spatiotemporal control. Here, we generated a magnetic-sensing Escherichia coli by driving the formation of iron-rich bodies into bacteria. We found that these bacteria could be spatially controlled by magnetic forces and sustained cell growth and division, by transmitting asymmetrically their magnetic properties to one daughter cell. We combined the spatial control of bacteria with genetically encoded-adhesion properties to achieve the magnetic capture of specific target bacteria as well as the spatial modulation of human cell invasions.
\end{abstract}


By programming and harnessing the cellular behavior of living organisms, synthetic biology tools enable broad applications ranging from basic biology to health and environment issues. Synthetic circuits have been developed for in vitro and in vivo diagnostics ${ }^{1}$, to produce novel material $2^{2,3}$, or to direct the assembly of synthetic multicellular systems ${ }^{4,5}$. For instance, programmed as whole-cell biosensors bacteria can report on environmental changes, detect specific molecules ${ }^{6,7}$, or monitor and diagnose diseases ${ }^{8-13}$. Bacteria can be further modified to act on their environment as illustrated by their use to target pathogenic bacteria ${ }^{14,15}$ or cancer cells $^{16-19}$.

Programming cells to be sensitive to non-biochemical stimuli, such as acoustic or magnetic waves, could expand their capacity to probe or act on their environment ${ }^{20}$. For instance, the integration of magnetic properties into living organisms could enable their spatial manipulation by magnetic forces, and their use as contrast agents for magnetic resonance imaging or as heat generator $^{21-27}$. As future perspectives, the magnetic localization of programmed bacteria may overcome their spatial dissemination driving to ineffective action, because of their dilution, or to biosafety issues. In this context, several strategies have been established to produce and use magnetic-sensing bacteria. First, magnetotactic bacteria are among the few living systems known to exploit magnetism by using their unique intracellular organelles, the magnetosomes ${ }^{28}$, to swim along the Earth's magnetic field. Despite several attempts to use magnetotactic bacteria ${ }^{29}$, they remained difficult to harness ${ }^{30}$ and to manipulate genetically. One second strategy consisted in building bacterial biohybrid systems either using magnetotactic bacteria carrying cargoparticles $^{31,32}$, or reciprocally, using a magnetic field to control the orientation of motile bacteria linked to magnetic beads ${ }^{33,34}$. A third approach aimed to magnetize naturally diamagnetic microorganisms or eukaryotic cells by over-expressing iron-storage ferritins or iron-binding proteins inside their cytoplasm. These bacteria could serve as containers favoring the formation of iron-oxide deposits when cells were fed with iron ${ }^{35-40}$. These studies showed that mineralized cells contained iron oxide deposits, can be detected using NMR, and can be magnetically sorted. However, to envision biotechnological applications using mineralized cells several important challenges still need to be achieved. Among primary questions, knowing how magnetic properties are transmitted during cell division, or whether magnetized cells are amenable for 
achieving defined biochemical functions while being magnetically manipulated, are essential elements that have not yet been solved.

To address such questions, we engineered and characterized MagEcoli, that are ironmineralized Escherichia coli bacteria expressing the iron-storage ferritin. We used MagEcoli to demonstrate that mineralized bacteria can be programmed to perform specific biochemical functions with spatiotemporal control using magnetic forces. First, we performed structural and magnetic characterization of MagEcoli and found that they contained iron oxide-enriched bodies conferring magnetic properties. Next, we showed that MagEcoli could be spatially manipulated when exposed to magnetic forces, with an efficiency that increased with iron loading. Moreover, MagEcoli divided and transmitted asymmetrically iron oxide ferritin-enriched bodies during division, thus avoiding the dilution of the magnetic properties during population growth. Finally, we combined the spatial control of MagEcoli, modified with genetically encoded-adhesion properties displayed on their outer membrane, to achieve the magnetic capture of specific target cells as well as the spatial modulation of human cell invasions. 


\section{Results}

\section{Genetic and chemical modifications to obtain a magnetic Escherichia Coli}

We aimed to induce the formation of iron-bearing particles within Escherichia Coli cytoplasm to provide magnetic properties to the bacteria. Our strategy to produce iron-rich inclusions in bacteria relied on a two-step process consisting first in overexpressing fluorescently-labelled ferritins and then supplying Fe(II) to the growth medium to biomineralize the bacteria. We chose the heterologous production of the iron-storage ferritins derived from Pyroccocus Furiosus ${ }^{41}$. Increasing Fe(II) concentration from 0 to $4 \mathrm{mM}$ resulted in reducing bacteria growth and the plateau value of their stationary phase (Fig. S1). After 16 hours of iron biomineralization, bacteria were washed and then characterized at the nanometer scale using transmission electron microscopy (TEM) images of cross sectioned mineralized E. coli. TEM images showed accumulation of a large electron-dense-deposit often localized at the extremity of the bacteria (Fig. 1A). The intracellular clusters were formed by the aggregation of small nanoparticles ( 3-5 nm, Fig. 1B), which was consistent with the cavity size of ferritin nanocages (8 $\mathrm{nm}$ inner diameter). The iron-rich clusters, quasi-spherical in shape and 100-300 $\mathrm{nm}$ in diameter, were localized in the cytosol of the bacteria. The electron diffraction pattern of the iron clusters showed that the nanoparticles were either amorphous or poorly crystallized (Fig. 1D). Their analysis by energy dispersive X-ray spectroscopy in scanning transmission electron microscopy (STEM) on $60 \mathrm{~nm}$ thick cross-sections of Escherichia Coli overexpressing ferritin proteins revealed iron, phosphorous and oxygen (Fig. 1C, E-H). This was confirmed by analyzing the minerals inside entire bacteria using cryo-TEM (Fig. S2A). As control, we imaged mineralized GFP-expressing E. coli which did not overexpress ferritins, and no-electron dense deposits were observed in those bacteria (Fig. S2B). In those conditions, only extra cellular precipitates were observed suggesting that the overexpression of ferritins was necessary to induce the formation of intracellular iron oxide nanoparticles (Fig. S2C).

Further quantitative characterization of the bacteria magnetic properties was achieved through the use of a magnetic properties measurement system (MPMS). The cells were subjected to a measurement of their mass-normalized magnetization at 5 and 300 Kelvin in magnetic inductions ranging between -2.5 and 2.5T (Fig. 1I). At room temperature (i.e., 300K), all samples exhibit a linear magnetization-versus-field behavior. The slope of the magnetization curve is negative for the sample without iron supplementation, which is inherent to the diamagnetic nature 
of most biological materials. Iron supplementation resulted in the addition of another linear component of positive slope, likely of paramagnetic nature. The maximum magnetization (in 2.5T) was increased by $0.01,0.02$ and $0.06 \mathrm{Am}^{2} / \mathrm{kg}$ for the 1,2 , and $4 \mathrm{mM} \mathrm{Fe}$ supplementations, respectively. The gain of magnetic susceptibility due to iron biomineralization is more evident when measuring at low temperature, as paramagnetism and other magnetic properties (ferro-, ferri-, antiferro-magnetism) increase in magnitude as temperature decreases, while diamagnetism remains constant. Measurements preformed at $5 \mathrm{~K}$ clearly display this magnetic enhancement. Compared to the zero-supplementation sample, maximum values of the magnetization increased by $0.09,0.21$, and $0.55 \mathrm{Am}^{2} / \mathrm{kg}$ for the 1,2 , and $4 \mathrm{mM} \mathrm{Fe}$ (II) supplementations, respectively. Altogether, those data highlight that magnetic E. coli contain iron minerals ferritin-enriched bodies conferring magnetic properties (referred as MagEcoli here after).

\section{Spatial manipulation and localization of bacteria upon magnetic forces}

To assess the possibility to spatially manipulate MagEcoli, we performed magnetophoretic experiments, which consist in observing the motion of non-motile bacteria submitted to magnetic forces. A mixture of biomineralized bacteria expressing mCherry-ferritin $\left(\right.$ MagEcoli $\left.{ }^{m C h e r r y}\right)$ and non-mineralized ones, expressing emGFP-ferritin (E. coli $\left.{ }^{G F P}\right)$ were diluted in a minimal medium with a density adjusted to prevent bacterial sedimentation. The mixture was then confined into water-in-oil droplets to minimize hydrodynamic flow perturbations and facilitate observation. Once formed, the bacteria droplets were injected into a capillary next to a permanent magnet generating a gradient of about $10 \mathrm{~T} . \mathrm{m}^{-1}$. Time-lapse observations showed that within few minutes the MagEcolim ${ }^{m \text { Cherry }}$ began to move in a direction oriented towards the magnet, whereas non-mineralized ones displayed no net motion (Fig. 2A). Moving bacteria eventually accumulated on the edge of the droplet as illustrated by the strong enhancement of mCherry signal intensity (Fig. 2A, Fig. S3A-C, Mov. S1 and S2). During this process, E. coli ${ }^{G F P}$ remained uniformly distributed within the droplet. After 90 minutes all magnetic bacteria were attracted (Fig. 2A, Fig. S3). In order to quantify the mobility of the MagEcoli, we tracked single bacterial trajectories within the droplet and computed their speed (Fig. 2B). This procedure was performed for respectively 1, 2, 3, and $4 \mathrm{mM} \mathrm{Fe(II)} \mathrm{added} \mathrm{during} \mathrm{the} \mathrm{biomineralization} \mathrm{step.} \mathrm{For}$ instance, single bacteria that were mineralized with $4 \mathrm{mM}$ iron displayed a directed motion towards the magnet position with a mean speed of about $5 \mu \mathrm{m} \cdot \mathrm{min}^{-1} \pm 2 \mu \mathrm{m} \cdot \mathrm{min}^{-1}$ (mean \pm 
standard deviation) (Fig. 2C). These mean speed values were also strongly correlated to the magnetic enhancement values deduced from MPMS measurements. This asymmetrical magnetic concentration procedure can be applied to force the co-localization of two bacterial populations, as exemplified in Fig. S4 where MagEcoli ${ }^{G F P}$ and MagEcolimCherry were strongly concentrated within the same area at the vicinity of the magnet.

Altogether, these data showed that MagEcoli can be spatially manipulated upon magnetic forces, with an efficiency that increases with the concentration of iron added during the biomineralization step. The magnetic concentration process is very specific of the state of biomineralization of the bacteria and did not affect non-magnetized bacteria diffusing in the mixture, allowing to perform basic operations such as magnetic separation and magnetic mixing (Fig. 2A and Fig. S4).

\section{How magnetic properties of MagEcoli propagate through cell division?}

Obtaining magnetized bacteria that can sustain cell division is of primary importance for basic understanding, and also to envision applications requiring magnetic manipulations of metabolically active bacteria as well as long term operations. We examined the transmission of magnetic properties after cell division by combining microscopy observations and magnetophoresis.

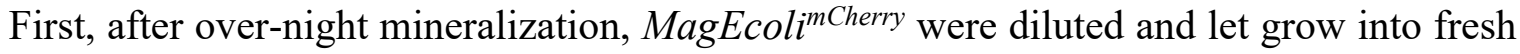
LB medium lacking iron supply. We observed ferritin-enriched bodies within bacteria at various growth stages: before new growth, and after 1, 2 and 3 divisions respectively. As the bacteria grew in absence of IPTG, mCherry fluorescence was directly correlated with the presence of ferritins expressed by the mother bacteria, which allowed us to monitor iron oxide enriched bodies (Fig. 3A). Before division, almost 100\% of bacteria displayed heterogeneous mCherry fluorescence accumulation (Fig. 3A). At this stage, we found bright fluorescent bodies localized at one or at both bacterial poles and coexisting with a diffuse fluorescence distributed within the cell body. These observations were in agreement with TEM acquisitions (Fig. 1A). When observing bacteria at a later stage of growth, the number of fluorescent bacteria decreased compared to non-fluorescent ones. After the $1^{\text {st }}$ division, $30 \%$ of the observed bacteria continued to display a fluorescent accumulation, whereas in contrast, the remaining bacteria showed a weak or no fluorescence signal (Fig. 3A). The fluorescent bacteria represent about $10 \%$ of the total 
bacteria after the third division, suggesting that bacteria asymmetrically transmitted their ferritinenriched bodies to daughter cells (Fig. 3A).

This asymmetric cell division model was also confirmed by monitoring the process of division using live microscopy (Fig. 3E, Mov. S3). MagEcoli ${ }^{m C h e r r y}$ that divided after biomineralization conserved their large bright inclusion bodies at the pole, leading to the transmission of the major part of mCherry-ferritin to one daughter cell only (Fig. S5).

Furthermore, after 24 hours of growth following the end of biomineralization, the remaining fluorescent bacteria moved as fast as the mineralized bacteria that had not undergone cell division (5 $\mu \mathrm{m} \cdot \mathrm{min}^{-1} \pm 3 \mu \mathrm{m} \cdot \mathrm{min}^{-1}$, 15 tracked trajectories, 3 different assays, (Fig. 3D)). We next quantified the evolution as a function of cell division of the ratio of bacteria remaining magnetic compared to the total number of growing bacteria. Mineralized mother bacteria were grown in a medium supplemented with IPTG to allow all newborn bacteria (magnetic and non-magnetic) to be monitored by fluorescence. The ratio of attraction towards the magnet of magnetic versus nonmagnetic bacteria drop from 100 to 58, 44, and, 26\% after the first three division steps (Fig. 3C). Altogether, these data showed that MagEcoli were still able to grow and divide. Only newborn bacteria maintaining iron oxide ferritin-enriched bodies inherited magnetic properties. This asymmetric division process avoids the dilution of the magnetic properties during population growth.

\section{MagEcoli with genetically encoded-adhesion properties for spatial control of cell capture and cell invasion}

Engineering the adhesion properties of cells offers multiple applications ranging from programming tissues, living materials, cell signaling, as well as designing whole-cell biosensors to detect specific analytes ${ }^{2-6,16,18}$. To envision applications combining the spatial control of bacteria and adhesion, we extended the capacity of MagEcoli to perform two distinct specific functions: the capture of specific bacteria and the invasion of human cells.

In order to capture, manipulate, or sort in space specific target bacteria, we have implemented in MagEcoli a genetically encoded surface-displaying adhesin system developed for controlling cell-cell adhesion ${ }^{5}$. This modular system displays on bacteria outer membrane nanobodies or antigens ${ }^{5}$. MagEcoli were transformed to produce on their outer membrane $\mathrm{Ag} 2$, an antigen based on a cell surface-bound adhesin and encoded as a single fusion protein designed 
to bind $\mathrm{Nb} 2$ nanobody-presenting bacteria ${ }^{5}$ (Fig. 4A). Expression of $\mathrm{Nb} 2$ and $\mathrm{Ag} 2$ was under control of anhydrotetracycline addition. When Ag2-producing MagEcoli (MagEcoli ${ }^{\text {Ag2/mCherry }}$ ) were mixed with $\mathrm{Nb2}$-producing bacteria $\left(E_{.} \operatorname{coli}^{\mathrm{Nb2} / G F P}\right)$, we could observe multicellular aggregates formed by few tens of cells with the same morphological patterns as previously demonstrated (Fig. 4B, left panel and S6). This indicated that the mineralization of bacteria did not preclude their adhesive properties. In absence of anhydrotetracycline, no aggregation was observed confirming the specificity of the adhesion system (Fig. 4B, right panel). To assess the capacity to capture and spatially manipulate target bacteria using MagEcoli, we mixed MagEcoli ${ }^{A g 2 / m C h e r r y}$ with E. coli ${ }^{\mathrm{Nb2} / G F P}$ in droplets and applied a permanent magnetic field as explained above (Fig. 4A). Remarkably, at the vicinity of the magnet, the concentration of E.coli ${ }^{N b 2 / G F P}$ was observed concomitantly with the one of MagEcolit ${ }^{A g 2 / m C h e r r y}$ (Fig. 4C and 4D). After about 30 min of attraction, we observed an increase in GFP as well as mCherry intensity at the vicinity of the magnet, indicating that $E$. $\operatorname{coli}^{N b 2 / G F P}$ were dragged along the magnetic gradient by the MagEcolitig2/mCherry. Moreover, no attraction was observed in the absence of

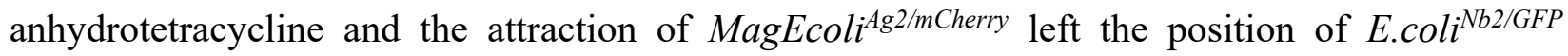
unaltered (Fig. 4D). With a closer look at the magnetophoresis experiments, we observed longrange transport of E. coli ${ }^{N b 2 / G F P}$ by MagEcolit ${ }^{A 2 / m C h e r r y}$ along magnetic force axis, indicating that enrichment by target cells was powered by MagEcoli transportation (Fig. 4E). Next, we computed the fraction of accumulated E. coli ${ }^{\mathrm{Nb2} / G F P}$ while attracting MagEcoli ${ }^{\text {Ag2/mCherry }}$, and found that $80 \%$ of MagEcolit ${ }^{A g 2 / m C h e r r y}$ and $20 \%$ of E. $\operatorname{coli}^{\mathrm{Nb2} / G F P}$ were attracted after 120 minutes, indicating an efficiency of capture of about 25\% (Fig. 4F and 4G). Altogether these data showed that MagEcoli can be programmed to capture and transport specific bacteria upon magnetic field application.

We next devised an assay to monitor the spatial localization of MagEcoli programmed to invade human cells. First, we expressed in MagEcoli the gene encoding Yersinia pseudotuberculosis invasin, an adhesive protein that is known to allow the invasion of cultured animal cells by otherwise non-invasive enterobacteria ${ }^{42}$. We verified that MagEcoli ${ }^{\text {inv/GFP }}$ (MagEcoli expressing invasin) were able to specifically recognize and invade human cells (Fig. 5A and S7). The invasiveness of MagEcoli $i^{\text {inv/GFP }}$ towards HeLa cells was quantified by gentamicin protection assay (Fig. S7): extracellular bacteria are killed by the antibiotic, while intracellular bacteria are protected due to the impermeability of host cells plasma membranes. 
Plating serial dilutions of cell lysates on LB-agar plates following 1 hour of gentamicin treatment thus enables an estimation of the number of internalized bacteria. We found that the internalization of MagEcolinv/GFP into HeLa cells did not differ significantly from that of the same bacteria that had been grown in absence of iron (Fig. S7), arguing that mineralization of invasive $E$. coli did not impair their ability to invade human cells. To demonstrate the magnetic localization of cell invasion, we placed a magnet under a dish containing HeLa cells in contact with MagEcoli ${ }^{i n / G F P}$ for 4 hours (Fig. 5B). After gentamicin treatment, cells were fixed and stained to image MagEcoli, actin filaments, as well as the cell nucleus. Strikingly, cells adhering in the vicinity of the magnetic field contained a larger number of MagEcoli in their cytoplasm than cells adhering far from the magnet. Moreover, the density of bacteria per cells increased with the gradient of magnetic field to reach about 8-fold of the bacteria density measured in absence of magnetic forces (Fig. 5C and 5D). Altogether, these data demonstrate our ability to target MagEcoli invasion to a specific zone with a magnetic field. 


\section{Discussion}

We demonstrate the spatial control of engineered bacteria mediated by magnetic forces and programmed to achieve specific tasks using modified surface-adhesion properties. Magnetic bacteria were engineered using a two-step processes, consisting first in the production of the iron storage ferritin in E. coli, and second, in growing these bacteria in an iron-rich medium. Iron mineralization of ferritin-expressing bacteria resulted in the formation of amorphous iron oxide minerals enriched in iron, oxygen and phosphorus. These MagEcoli bacteria display paramagnetic properties that increase with the amount of iron supplemented during bacteria growth. In contrast, biomineralized bacteria that did not over-express ferritins were not exhibiting any detectable intracellular iron oxide particles, but showed extracellular iron deposits. MPMS measurements showed that biomineralized control E. coli displayed a diamagnetic signal, suggesting that the paramagnetic contribution of MagEcoli is mainly due to intracellular iron oxide minerals. These data suggest a model in which ferritin-expressing E. coli hyperaccumulate iron metals that form iron-oxide minerals stored into ferritin-enriched bodies, with a chemical and crystal-structure that are constrained by the physical-chemistry state of the E. coli cytoplasmic in terms of $\mathrm{pH} /$ redox conditions.

We next demonstrate that MagEcoli can be concentrated using magnetic forces to generate spatial heterogeneity in bacterial concentration. For instance, when confined in a millimeter-size confined environment, MagEcoli could be physically separated from a nonmagnetic bacteria population or, in contrast, forced to mix together with a second magnetic bacterial strain in a specific area.

To investigate how cell division could impact the magnetic properties of MagEcoli, we studied how ferritin-enriched bodies and magnetic properties propagated when bacteria divided. We found that MagEcoli transmitted asymmetrically their ferritin-enriched bodies to only one daughter cell. The proportion of attracted magnetic bacteria by the magnet dropped concomitantly with the cell division number to reach about $10 \%$ after three divisions. This corroborates a model for which the main magnetic properties were inherited by one daughter cell, consequently resulting in the maintenance of a constant population of MagEcoli in regard to a growing non-magnetic population of bacteria. Interestingly, this mechanism limits the dilution of 
the magnetic properties, which would in contrast be expected if mineralized ferritin bodies would equally be distributed between the two daughter cells.

One essential aspect when envisioning applications of MagEcoli was to assess how these bacteria could be further programmed to perform specific biochemical functions. By expressing genetically encoded surface adhesion proteins, we studied the spatial localization of MagEcoli programmed to recognize and adhere to specific bacteria or to invade a mammalian host. We first demonstrated the spatial manipulation of MagEcoli acting as a surface-displaying antigen to adhere specifically to non-magnetic nanobody-displaying bacteria. We found that MagEcoli can capture and transport target bacteria along a magnetic force axis to eventually drive their accumulation. Such properties illustrate potential perspectives for biotechnological purposes as MagEcoli could be programmed and magnetically manipulated to transport cargos, for patterning living materials, or as whole-cell biosensors for in vitro or in vivo diagnostic. In a second application, we demonstrated the spatial modulation of cell invasion in a magnetic field by programming MagEcoli to invade human cells. The magneto-localization of infection could provide a novel tool for basic studies of host-pathogen interactions. One horizon consists in the spatiotemporal control of bacteria programmed as delivery vehicles to release cytotoxic molecules into cancer cells. 


\section{Acknowledgements}

The authors acknowledge Ludovic Jullien, Guillaume Morin and the members of the Biophysical Chemistry group of the École normale supérieure for fruitful discussion. We thank Chakib Djediat (MNHN) for help with TEM sample preparation.

Funding: This work was supported by the ANR (ANR-16-CE09-0002-Nanoheaters), the CNRS, and Ecole Normale Supérieure.

\section{Author's contributions}

M.A, F.G, and Z.G conceived the project and analysed results of the study. M.A carried out and analysed most of the experiments. WA.W contributed to the initial design of the magnetophoresis experiments. WA.W, J.M Guignier and F.G carried out and analysed the TEM and energy dispersive X-ray spectroscopy experiments. Y.G carried out and analysed the MPMS data. M.A and O.E carried out live microscopy of bacteria division. A.L carried out the assessment of cell invasion by gentamicin protection assay. M.A and A.L performed the spatial modulation of cell invasion. M.A and E.D performed the magnetic capture assay. M.A and Z.G wrote the manuscript and all authors were involved in revising it critically for important intellectual content.

\section{Conflict of Interest}

M.A., WA.W, F.G and Z.G. have filed a provisional patent EP19188019.4 "MAGNETIC BACTERIA, NON-THERAPEUTIC AND THERAPEUTIC USES THEREOF”, on the 24 July 2019.

\section{Supporting Information}

Table S1. displays the list of the plasmid used in the study.

Figures S1. - S7. represent further characterizations of MagEcoli (growth curved, cryo-TEM observations, epifluorescence images of dividing MagEcoli), other magnetophoresis characterization and supplementary data concerning the two proof-of-concept assays.

Movies S1. - S3. are magnetophoresisor division movies of MagEcoli. 


\section{Materials and Methods}

\section{Chemicals}

Kanamycin, Chloramphenicol, Ampicillin, Spectinomycin, Mohr's Salt, LB broth, M9 broth, Glycerol, Agar, Sucrose, IPTG, Mineral oil, PBS, and anhydrotetracycline were purchased from SIGMA-ALDRICH®. Arlacel P135 was purchased from CRODA®; Optiprep ${ }^{\mathrm{TM}}$ was purchased from StemCell ${ }^{\circledR}$. Vitrex ${ }^{\circledR}$ was purchased from VWR $\AA$.

\section{DNA plasmids and strains}

The list of the plasmids used in this studie are reported in Table S1. The Pyrococcus Furiosus ferritins were fused at their N-terminal to mCherry or Emerald GFP (EmGFP) and were cloned into pet28, pGBM4. The ability of E. coli to be internalized into epithelial cells was granted by the pRI203 plasmid allowing the expression of the invasin gene from Yersinia pseudotuberculosis (inv) in a pBR325 vector.

\section{Models}

E. coli bacteria were purchased at Merck for Rosetta (DE3)pLysS, at New England Biolabs for BL21 and dH10ß. E. coli MG1655 come from Blattner et al., 1997.

HeLa cell line come from ATCC (CCl-2) as well as LoVo cell line (CCL-229).

\section{Transformation:}

All plasmids were incorporated into electro-competent bacteria (Rosetta or MG1655) via electroporation.

\section{Biomineralization protocol}

Plasmids used for biomineralization, and their corresponding antibiotics, are listed in table S1. Stock solution of antibiotics were made at 1000X: kanamycin $(50 \mathrm{mg} / \mathrm{mL}$ in water), ampicillin $(100 \mathrm{mg} / \mathrm{mL}$ in water), chloramphenicol $(34 \mathrm{mg} / \mathrm{mL}$ in ethanol), spectinomycin $(100 \mathrm{mg} / \mathrm{mL}$ in water) and stored at $-20^{\circ} \mathrm{C}$. Antibiotics were diluted to the LB medium and added at every step of bacterial culture or biomineralization. 
As a source of iron II, Mohr salt was used and kept under inert condition. At each step of iron addition, a fresh solution of Mohr salt was made in water at a concentration of $100 \mathrm{mM}$. This solution was immediately added to the bacteria and no kept longer than 10 minutes.

Bacteria were grown overnight in LB medium with the corresponding antibiotics (Table S1) until they reached the steady state (precultures). The next day, they were diluted and grown into fresh LB medium with antibiotics at $37{ }^{\circ} \mathrm{C}$ under agitation for approximately 2 hours, until they

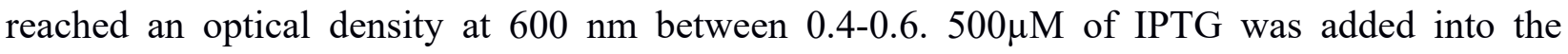
medium when growing bacteria transformed with the pet28 derived plasmids. Bacteria were incubated at $37^{\circ} \mathrm{C}$ under agitation for $30 \mathrm{~min}$. Next, Fe(II) was added to the bacteria to a final concentration of 1 to $4 \mathrm{mM}$. Bacteria were grown overnight at $37^{\circ} \mathrm{C}$ (about 16 hours $\pm 10 \%$ ). The next morning, bacterial O.D. at $600 \mathrm{~nm}$ was measured. Correction from the absorption of iron was performed using a blank measured with LB containing Fe(II) at 0 to $4 \mathrm{mM}$. Finally, bacteria were washed after centrifugation to remove iron oxide residues from the LB and placed into the desired buffer (free from antibiotics, for observation or further experiments).

\section{Growth curve}

Overproducing mCherry-ferritin E. coli were grown overnight in LB medium supplemented with kanamycin $(50 \mu \mathrm{g} / \mathrm{mL})$ and chloramphenicol $(34 \mu \mathrm{g} / \mathrm{mL})$, until they reached the steady state (precultures). The next day, bacteria were diluted 1:50 in fresh LB supplemented with kanamycin (50 $\mu \mathrm{g} / \mathrm{mL})$, chloramphenicol $(34 \mu \mathrm{g} / \mathrm{mL})$ and $500 \mu \mathrm{M}$ of IPTG. $200 \mu \mathrm{L}$ of bacteria were deposited into a $96 \mu \mathrm{L}$-well microplate (in triplicate for each condition). Measured were taken at $600 \mathrm{~nm}$ with a TECAN each 10 minutes for 20 hours. After 2 hours, when bacteria reached an OD of about $0.3-0.4, \mathrm{Fe}(\mathrm{II})$ was supplemented in the medium to reach a final concentration of 0 , 2, 3 and $4 \mathrm{mM}$. As a source of iron, Mohr salt, stored under inert condition, was freshly made in water at a stock concentration of $100 \mathrm{mM}$. A blank of LB mixed with Fe(II) at 0, 2, 3 and $4 \mathrm{mM}$ was taken into account to subtract the O.D. due to iron precipitation over time.

\section{Ultrathin section transmission electron microscopy}

E. coli cells were fixed for 2 hours in $2 \%$ glutaraldehyde in $0.1 \mathrm{M}$ Sörensen phosphate buffer and washed with iso osmolar phosphate buffer. Afterwards the samples were fixed for 1 hour with $1 \%$ of osmium tetroxide and washed with iso osmolar phosphate buffer. After repeated washing, 
the samples were dehydrated through an ethanol series and embedded in epoxy resin (ERL 42O6) in beem capsules, which polymerized at $55^{\circ} \mathrm{C}$ for 48 hours. Ultrathin sections were obtained using a diatome diamond knife in a Leica UCT ultramicrotome and deposited onto a 300 mesh carbon-coated grid. TEM images were obtained on a Jeol $2100 \mathrm{~F}$ microscope. This machine, operating at $200 \mathrm{kV}$, is equipped with a field emission gun, an ultra-high resolution pole piece, and an ultrathin window JEOL detector.

\section{Cryo-Transmission Electron Microscopy (cryo-TEM) images}

A drop of bacteria solution was deposited on "quantifoil" $($ (Quantifoil Micro Tools GmbH, Germany) carbon membrane. The excess of liquid on the membrane was absorbed with a filter paper and the membrane was quench-frozen quickly in liquid ethane to form a thin vitreous ice film. Once placed in a Gatan 626 cryo-holder cooled with liquid nitrogen, the samples were transferred in the microscope and observed at low temperature $\left(-180{ }^{\circ} \mathrm{C}\right)$. Cryo-TEM images were recorded on ultrascan 2k x 2k CCD camera (Gatan, USA), using a LaB 6 JEOL JEM2100 (JEOL, Japan) cryo microscope operating at $200 \mathrm{kV}$ with a JEOL low dose system (Minimum Dose System, MDS) to protect the thin ice film from any irradiation before imaging and reduce the irradiation during the image capture.

\section{Magnetic characterization}

Magnetic characterization of the samples was performed using Quantum Design incorporated Magnetic Properties Measurements System (MPMS-XL 5 evercool). The MPMS allows low temperature measurements of magnetic moments and magnetic susceptibility down to $2 \mathrm{~K}$. Prior to measurements, dry powdered samples were placed in gelatin capsules and inserted in $5 \mathrm{~mm}$ in diameter non-magnetic plastic straws. Measured magnetic moments were mass normalized in order to calculate magnetizations, allowing comparisons between samples.

\section{Magnetophoresis set up}

For the magnetophoresis experiments, freshly mineralized bacteria were washed twice in antibiotic free M9 medium. Next, bacteria were concentrated to an optical density of approximately 6, when not mentioned. For O.D. measurements, the blank was made of M9 medium. Then bacteria were diluted 10 times with M9 supplemented with sucrose $(500 \mathrm{mg}$ of 
sucrose for $700 \mu \mathrm{L}$ of M9), to prevent sedimentation. A water-in-oil emulsion was formed by mixing up $99 \mu \mathrm{L}$ of mineral oil supplemented with a block copolymer at $0.4 \mathrm{~g} / \mathrm{L}$ (ArlacelP135) and $1 \mu \mathrm{L}$ of bacteria. The emulsion was inserted into a capillary ( $1 \mathrm{~mm}$ of diameter) fixed on a microscopic slide $(32 \times 40 \mathrm{~mm})$. The capillary was sealed with Vitrex ${ }^{\circledR}$ and a neodymium magnet was placed at one side (cubic magnet $\mathrm{NdFeB} 3 \mathrm{~mm}$, Supermagnet), the $\mathrm{N}-\mathrm{S}$ axis being perpendicular to the capillary's direction. Observations were made using epifluorescence microscopy.

\section{Study of the transmission of magnetism as a function of cell division with magnetophoresis} MagEcoli (4 mM of $\mathrm{Fe}(\mathrm{II})$ ) were diluted to an optical density of around 0.1 into fresh LB medium. Depending on the context, $500 \mu \mathrm{M}$ of IPTG and kanamycin were added to induce the constant production of mCherry-ferritin during growth. Once the bacteria reached the desired optical density (corresponding to 1, 2 or 3 divisions), magnetophoresis tests were performed with bacteria washed twice and concentrated into M9 medium.

\section{Observation of bacteria as a function of cell division}

To perform visualization of bacteria during cell division, mineralized bacteria ( $2 \mathrm{mM}$ of $\mathrm{Fe}(\mathrm{II})$ ) were washed in LB medium and then diluted into a fresh LB medium (kanamycin) to 0.1 O.D. Bacteria grow at $37^{\circ} \mathrm{C}$ under agitation. For single-cell observation, bacteria at the desired optical density were washed and concentrated into M9 medium. They were spread on an agarose pad ( $2 \%$ agarose LB) and observed by fluorescence microscopy.

\section{Live observation of single dividing bacteria}

MagEcoli (2 $\mathrm{mM}$ of Fe(II) and $0 \mathrm{mM}$ of $\mathrm{Fe}(\mathrm{II})$ for the control without iron) were washed in LB medium and then spread under an agar pad (1\% agar LB). Time-lapse microscopy was performed using a confocal spinning disk (W1 Yokogawa) on an inverted Zeiss Axio Imager microscope at $63 \times$ magnification controlled by Metamorph (Molecular Imaging) and a CMOS camera (Hamamatsu). Metamorph autofocus control was used at each time point on the phase contrast signal. Images were acquired every $2 \mathrm{~min}$ for $5 \mathrm{~h}$ at $37^{\circ} \mathrm{C}$. Four positions were observed simultaneously for each experiment, with $20-50$ cells per position. 


\section{Magnetic capture by MagEcoli}

Ag2-producing MagEcoli (MagEcolitig2/mCherry): MG1655 bacteria were co-transformed with both pDSG419 and pGBM4_mCherry-ferritin plasmids, and then mineralized with $4 \mathrm{mM}$ or Fe(II) in the presence of $100 \mathrm{ng} / \mathrm{mL}$ of anhydrotetracycline and antibiotics. Nb2-producing bacteria (E.coli ${ }^{N b 2 / G F P}$ ): MG1655 were co-transformed with pDSG375 and pGBM4-GFP-Ferritin plasmids and were diluted in LB with $100 \mathrm{ng} / \mathrm{mL}$ of anhydrotetracycline and antibiotics for overnight preculture. The next day, both populations of bacteria were washed twice with antibiotic free M9 medium. The two strains were mixed in M9 medium at a density of around 0.4 (for aggregates visualization) or into M9 medium supplemented with sucrose (500 mg of sucrose for $700 \mu \mathrm{L}$ of M9) at a density of around 0.4 (for immediate test of magnetophoresis). Adhesion experiments were made at a ratio of bacteria of 1:1. After several hours, the mixes in M9 let at room temperature were observed in glass chip chambers to monitor aggregation. On the same day, a first set of control experiments were performed with non-adhering bacteria using MagEcolitig2/mCherry and E.coli ${ }^{\text {Nb2/GFP }}$ that grown without anhydrotetracycline. A second set of

control experiments was performed with adherent but non-magnetic bacteria using E.coli ${ }^{A 2 / m C h e r r y}$ and E.coli ${ }^{N b 2 / G F P}$ (without iron addition). Observation was performed using epifluorescence acquisitions.

\section{Assessment of cell invasion by gentamicin protection}

LoVo cells were grown in monolayer in 24-well plates in D-MEM medium containing $10 \%$ fetal bovine serum (FBS) until they reached a density of $1.10^{5}$ cell per well. MagEcoli ${ }^{\text {inv/GFP }}$ consisted in mineralized BL21 (4mM Fe(II)) cotransformed with the pRI203 plasmid expressing Yersinia pseudotuberculosis inv gene and the pet28_GFP-ferritin plasmid. E.coli ${ }^{\text {inv/GFP }}$ consisted in BL21 cotransformed with the pRI203 plasmid expressing Yersinia pseudotuberculosis inv gene and the pet28_GFP-ferritin plasmid and that were not mineralized. Both MagEcoli ${ }^{\text {inv/GFP }}$ and E.coli ${ }^{\text {inv/GFP }}$ were pelleted by centrifugation at $6,000 \times g$, then washed with pre-warmed PBS and diluted in DMEM without serum containing 20\% Optiprep ${ }^{\mathrm{TM}}$ (to prevent sedimentation) to an optical density of 0.1 . Cell culture wells were washed once with $500 \mu \mathrm{L}$ of pre-warmed D-MEM, then $200 \mu 1$ of each inoculum was dispensed onto the cell culture monolayers, and left to incubate for 4 hours at $37^{\circ} \mathrm{C}$ under $5 \% \mathrm{CO}_{2}$ atmosphere. The multiplicity of infection (MOI) was estimated by plating serial dilutions of each inoculum on LB-agar plates, and found to be in the range of 100 for both 
conditions. After 4 hours, the inoculum was washed away with $500 \mu$ l of pre-warmed D-MEM containing $40 \mu \mathrm{g} / \mathrm{ml}$ of gentamicin, then replaced with D-MEM containing $10 \%$ FBS and 40 $\mu \mathrm{g} / \mathrm{ml}$ for 1 hour. This incubation allows the complete killing of extracellular bacteria by gentamicin, while intracellular bacteria are protected from the antibiotic by the plasma membrane. After 1 hour, cell monolayers were washed with $500 \mu$ of pre-warmed PBS, then lysed by adding $200 \mu \mathrm{l}$ of $4^{\circ} \mathrm{C}$ sterile water to each well. Serial dilutions of cell lysates were plated on LB-agar plates to quantify the number of intracellular bacteria in each well. Data are provided as the percentage of the inoculum having entered cells and represent the results of double counting from six different wells per condition in a representative experiment out of three independent experiments.

\section{Spatial modulation of cell invasion by MagEcoli}

Experiments were performed with MagEcoli ${ }^{\text {inv/GFP }}$ and as control with E.coli ${ }^{\text {inv/mCherry }}$. Bacteria were washed with PBS just after overnight growth and were diluted in PBS $+20 \%$ Optiprep ${ }^{\text {тм }}$ (to prevent sedimentation) to an optical density of 0.02 . On each cell chamber containing confluent HeLa cells, $2 \mathrm{~mL}$ of a mixture of MagEcoli ${ }^{\text {inv } / G F P}$ and E.coli ${ }^{\text {inv/mCherry }}$ in PBS were added. Each chamber was placed above a $\mathrm{NdFeB}$ magnet (cubic $5 \mathrm{~mm}$, Supermagnet) in an incubator providing a constant temperature of $37^{\circ} \mathrm{C}$ and carbon dioxide supply, for 4 hours. After incubation, the PBS was removed and the chambers were filled with $2 \mathrm{~mL}$ of DMEM and gentamicin $(40 \mu \mathrm{g} / \mathrm{mL})$. Immediately, it was replaced by $2 \mathrm{ml}$ of DMEM with gentamicin (40 $\mu \mathrm{g} / \mathrm{mL}$ ) and FBS $10 \%$. The system was let 1 hour at $37^{\circ} \mathrm{C}$ to kill all extracellular bacteria. Then, after washing with PBS, cells were fixed with paraformaldehyde (PFA) 4\%. After washing with PBS, cells were permeabilized with PBS and Triton $0.5 \%$ and stained with DAPI and Actistain 647 for 1 hour. Another strain was tested as represented on the images of figure 5A: MagEcoli ${ }^{i n v / G F P}$ were added to Lovo cells for 1 hour of infection.

\section{Microscopy observations}

Magnetophoresis experiments were observed using IX81 (Olympus) epifluorescence microscope equipped with an EM-CCD camera (electron multiplying CCD, C9100-13 or C9100-02, Hamamatsu, Corporation), a LED for illumination (Spectra X, Lumencor), and with x10, x20, 60x oil objectives. Microscopes were controlled by MicroManager or SimplePCI software. 


\section{Data analysis}

Image analysis were made using Fiji. Running $\mathrm{Z}$ projector plug-in was used to observe superimposed trajectories in the magnetophoresis assays. For tracking the bacteria position, 60 trajectories were analyzed for each biomineralization condition (1 to $4 \mathrm{mM} \mathrm{Fe}(\mathrm{II})$ ) using Excel and Matlab. Experiments were performed twice for each concentration of iron on different samples.

To quantify the number of bacteria under agar-gel, Cell-counter plug-in was used on composite images (merged of bright field and mCherry). The assay of bacterial growth was duplicated on a different day. For each division of each assay, we counted around 1000 bacteria. The 1000 bacteria counted came from different field on the slide.

For Fig. 3C, to quantify the ratio of attraction towards the magnet of magnetic versus nonmagnetic bacteria as a function of cell division, we measured the intensity of the region of interest corresponding to fluorescent bacteria accumulating at the vicinity of the droplet 90 minutes after starting magnetophoresis. This value was normalized by the intensity on the whole droplet at initial time (right after starting magnetophoresis). Measurements were performed on three different conditions acquired for different biomineralization experiments (3 movies).

For Fig. S3, Fig. 4F and Fig. 4G, to quantify the number of bacteria in both areas, we measured the intensity in the region of interest at each minute. We normalized this value by the intensity of the whole droplet at initial time (right after starting the magnetophoresis). We substracted the background in the measurements. We normalized the data by assuming that the sum of bacteria in both areas was equal to $100 \%$.

To quantify the number of bacteria invading HeLa cells, we counted the number of nucleus and bacteria on binary-transformed images (after applying a manual threshold). Analysis were performed on 4 different areas crossing the cell chamber on the same representative sample, and a Gaussian fit was applied for each zone of observation.

For the movie of dividing bacteria (Movie S3), the bleaching of mCherry fluorescence was corrected with the FIJI plug-in "bleach correction", using the simple ratio method and a background intensity level of 110 . 


\section{Statistical analysis}

Data treatment and graphic generations were performed with Excel (Microsoft) and MATLAB (Mathworks). For Fig. 2C, Fig. 3B, Fig. 3C, Student's t-test (parametric test to compare two observed means) was performed with ttest2 function with Matlab. Error bars always show the Standard Deviation (SD). For Fig. S7. the values were obtained for 12 technical replicates from a representative invasion assays among three independent experiments, their means and standard deviations were plotted. The probability $p$ of rejection of the null hypothesis was assessed using a two-tailed Student's $t$-test.

\section{Data availability:}

All data are available from the corresponding author upon request. 


\section{References:}

(1) Slomovic, S.; Pardee, K.; Collins, J. J. Synthetic Biology Devices for in Vitro and in Vivo Diagnostics. Proc. Natl. Acad. Sci. U. S. A. 2015.

https://doi.org/10.1073/pnas.1508521112.

(2) Nguyen, P. Q.; Botyanszki, Z.; Tay, P. K. R.; Joshi, N. S. Programmable Biofilm-Based Materials from Engineered Curli Nanofibres. Nat. Commun. 2014. https://doi.org/10.1038/ncomms5945.

(3) Chen, A. Y.; Deng, Z.; Billings, A. N.; Seker, U. O. S.; Lu, M. Y.; Citorik, R. J.; Zakeri, B.; Lu, T. K. Synthesis and Patterning of Tunable Multiscale Materials with Engineered Cells. Nat. Mater. 2014. https://doi.org/10.1038/nmat3912.

(4) Toda, S.; Blauch, L. R.; Tang, S. K. Y.; Morsut, L.; Lim, W. A. Programming SelfOrganizing Multicellular Structures with Synthetic Cell-Cell Signaling. Science (80-. ). 2018, 361 (6398), 156-162. https://doi.org/10.1126/science.aat0271.

(5) Glass, D. S.; Riedel-Kruse, I. H. A Synthetic Bacterial Cell-Cell Adhesion Toolbox for Programming Multicellular Morphologies and Patterns. Cell 2018, 174 (3), 649-658.e16. https://doi.org/10.1016/j.cell.2018.06.041.

(6) Kylilis, N.; Riangrungroj, P.; Lai, H. E.; Salema, V.; Fernández, L. Á.; Stan, G. B. V.; Freemont, P. S.; Polizzi, K. M. Whole-Cell Biosensor with Tunable Limit of Detection Enables Low-Cost Agglutination Assays for Medical Diagnostic Applications. ACS Sensors 2019, 4 (2), 370-378. https://doi.org/10.1021/acssensors.8b01163.

(7) Van Der Meer, J. R.; Belkin, S. Where Microbiology Meets Microengineering: Design and Applications of Reporter Bacteria. Nature Reviews Microbiology. 2010. https://doi.org/10.1038/nrmicro2392.

(8) Mimee, M.; Nadeau, P.; Hayward, A.; Carim, S.; Flanagan, S.; Jerger, L.; Collins, J.; McDonnell, S.; Swartwout, R.; Citorik, R. J.; Bulović, V.; Langer, R.; Traverso, G.; Chandrakasan, A. P.; Lu, T. K. An Ingestible Bacterial-Electronic System to Monitor Gastrointestinal Health. Science (80-. ). 2018. https://doi.org/10.1126/science.aas9315.

(9) Riglar, D. T.; Giessen, T. W.; Baym, M.; Kerns, S. J.; Niederhuber, M. J.; Bronson, R. T.; Kotula, J. W.; Gerber, G. K.; Way, J. C.; Silver, P. A. Engineered Bacteria Can Function in the Mammalian Gut Long-Term as Live Diagnostics of Inflammation. Nat. Biotechnol. 
2017. https://doi.org/10.1038/nbt.3879.

(10) Riglar, D. T.; Silver, P. A. Engineering Bacteria for Diagnostic and Therapeutic Applications. Nat. Rev. Microbiol. 2018, 16 (4), 214-225.

https://doi.org/10.1038/nrmicro.2017.172.

(11) Daeffler, K. N.; Galley, J. D.; Sheth, R. U.; Ortiz-Velez, L. C.; Bibb, C. O.; Shroyer, N. F.; Britton, R. A.; Tabor, J. J. Engineering Bacterial Thiosulfate and Tetrathionate Sensors for Detecting Gut Inflammation. Mol. Syst. Biol. 2017. https://doi.org/10.15252/msb.20167416.

(12) Certain, L. K.; Way, J. C.; Pezone, M. J.; Collins, J. J. Using Engineered Bacteria to Characterize Infection Dynamics and Antibiotic Effects In Vivo. Cell Host Microbe 2017. https://doi.org/10.1016/j.chom.2017.08.001.

(13) Mimee, M.; Tucker, A. C.; Voigt, C. A.; Lu, T. K. Programming a Human Commensal Bacterium, Bacteroides Thetaiotaomicron, to Sense and Respond to Stimuli in the Murine Gut Microbiota. Cell Syst. 2015. https://doi.org/10.1016/j.cels.2015.06.001.

(14) Gupta, S.; Bram, E. E.; Weiss, R. Genetically Programmable Pathogen Sense and Destroy. ACS Synth. Biol. 2013, 2 (12), 715-723. https://doi.org/10.1021/sb4000417.

(15) Hwang, I. Y.; Koh, E.; Wong, A.; March, J. C.; Bentley, W. E.; Lee, Y. S.; Chang, M. W. Engineered Probiotic Escherichia Coli Can Eliminate and Prevent Pseudomonas Aeruginosa Gut Infection in Animal Models. Nat. Commun. 2017, 8, 1-11. https://doi.org/10.1038/ncomms15028.

(16) Anderson, J. C.; Clarke, E. J.; Arkin, A. P.; Voigt, C. A. Environmentally Controlled Invasion of Cancer Cells by Engineered Bacteria. J. Mol. Biol. 2006, 355 (4), 619-627. https://doi.org/10.1016/j.jmb.2005.10.076.

(17) Din, M. O.; Danino, T.; Prindle, A.; Skalak, M.; Selimkhanov, J.; Allen, K.; Julio, E.; Atolia, E.; Tsimring, L. S.; Bhatia, S. N.; Hasty, J. Synchronized Cycles of Bacterial Lysis for in Vivo Delivery. Nature 2016, 536 (7614), 81-85. https://doi.org/10.1038/nature18930.

(18) Piñero-Lambea, C.; Bodelón, G.; Fernández-Periáñez, R.; Cuesta, A. M.; Álvarez-Vallina, L.; Fernández, L. Á. Programming Controlled Adhesion of E. Coli to Target Surfaces, Cells, and Tumors with Synthetic Adhesins. ACS Synth. Biol. 2015, 4 (4), 463-473. https://doi.org/10.1021/sb500252a. 
(19) Danino, T.; Prindle, A.; Kwong, G. A.; Skalak, M.; Li, H.; Allen, K.; Hasty, J.; Bhatia, S. N. Programmable Probiotics for Detection of Cancer in Urine. Sci. Transl. Med. 2015, 7 (289). https://doi.org/10.1126/scitranslmed.aaa3519.

(20) Piraner, D. I.; Farhadi, A.; Davis, H. C.; Wu, D.; Maresca, D.; Szablowski, J. O.; Shapiro, M. G. Going Deeper: Biomolecular Tools for Acoustic and Magnetic Imaging and Control of Cellular Function. Biochemistry. 2017. https://doi.org/10.1021/acs.biochem.7b00443.

(21) Mannix, R. J.; Kumar, S.; Cassiola, F.; Montoya-Zavala, M.; Feinstein, E.; Prentiss, M.; Ingber, D. E. Nanomagnetic Actuation of Receptor-Mediated Signal Transduction. Nat Nanotechnol 2008, 3, 36-40. https://doi.org/nnano.2007.418 [pii] 10.1038/nnano.2007.418.

(22) Li, T. L.; Wang, Z.; You, H.; Ong, Q.; Varanasi, V. J.; Dong, M.; Lu, B.; Paşca, S. P.; Cui, B. Engineering a Genetically Encoded Magnetic Protein Crystal. Nano Lett. 2019. https://doi.org/10.1021/acs.nanolett.9b02266.

(23) Liße, D.; Monzel, C.; Vicario, C.; Manzi, J.; Maurin, I.; Coppey, M.; Piehler, J.; Dahan, M. Engineered Ferritin for Magnetogenetic Manipulation of Proteins and Organelles Inside Living Cells. Adv. Mater. 2017, 29 (42), 1-7. https://doi.org/10.1002/adma.201700189.

(24) Rao, S.; Chen, R.; LaRocca, A. A.; Christiansen, M. G.; Senko, A. W.; Shi, C. H.; Chiang, P. H.; Varnavides, G.; Xue, J.; Zhou, Y.; Park, S.; Ding, R.; Moon, J.; Feng, G.; Anikeeva, P. Remotely Controlled Chemomagnetic Modulation of Targeted Neural Circuits. Nature Nanotechnology. 2019. https://doi.org/10.1038/s41565-019-0521-z.

(25) Hoffmann, C.; Mazari, E.; Lallet, S.; Le Borgne, R.; Marchi, V.; Gosse, C.; Gueroui, Z. Spatiotemporal Control of Microtubule Nucleation and Assembly Using Magnetic Nanoparticles. Nat Nano 2013, 8, 199-205. https://doi.org/http://www.nature.com/nnano/journal/v8/n3/abs/nnano.2012.246.html\#supp lementary-information.

(26) Du, V.; Luciani, N.; Richard, S.; Mary, G.; Gay, C.; Mazuel, F.; Reffay, M.; Menasché, P.; Agbulut, O.; Wilhelm, C. A 3D Magnetic Tissue Stretcher for Remote Mechanical Control of Embryonic Stem Cell Differentiation. Nat. Commun. 2017. https://doi.org/10.1038/s41467-017-00543-2.

(27) Van de Walle, A.; Sangnier, A. P.; Abou-Hassan, A.; Curcio, A.; Hémadi, M.; Menguy, N.; Lalatonne, Y.; Luciani, N.; Wilhelm, C. Biosynthesis of Magnetic Nanoparticles from 
Nanodegradation Products Revealed in Human Stem Cells. Proc. Natl. Acad. Sci. U. S. A. 2019. https://doi.org/10.1073/pnas.1816792116.

(28) Arakaki, A.; Nakazawa, H.; Nemoto, M.; Mori, T.; Matsunaga, T. Formation of Magnetite by Bacteria and Its Application. J. R. Soc. Interface 2008, 5 (26), 977-999. https://doi.org/10.1098/rsif.2008.0170.

(29) Roda, A.; Cevenini, L.; Borg, S.; Michelini, E.; Calabretta, M. M.; Schüler, D. Bioengineered Bioluminescent Magnetotactic Bacteria as a Powerful Tool for Chip-Based Whole-Cell Biosensors. Lab Chip 2013, 13 (24), 4881-4889.

https://doi.org/10.1039/c31c50868d.

(30) Xie, J.; Chen, K.; Chen, X. Production, Modification and Bio-Applications of Magnetic Nanoparticles Gestated by Magnetotactic Bacteria. Nano Res. 2009, 2 (4), 261-278. https://doi.org/10.1007/s12274-009-9025-8.

(31) Stanton, M. M.; Park, B. W.; Vilela, D.; Bente, K.; Faivre, D.; Sitti, M.; Sánchez, S. Magnetotactic Bacteria Powered Biohybrids Target E. Coli Biofilms. ACS Nano 2017, 11 (10), 9968-9978. https://doi.org/10.1021/acsnano.7b04128.

(32) Felfoul, O.; Mohammadi, M.; Taherkhani, S.; de Lanauze, D.; Zhong Xu, Y.; Loghin, D.; Essa, S.; Jancik, S.; Houle, D.; Lafleur, M.; Gaboury, L.; Tabrizian, M.; Kaou, N.; Atkin, M.; Vuong, T.; Batist, G.; Beauchemin, N.; Radzioch, D.; Martel, S. Magneto-Aerotactic Bacteria Deliver Drug-Containing Nanoliposomes to Tumour Hypoxic Regions. Nat. Nanotechnol. 2016, 11 (11), 941-947. https://doi.org/10.1038/nnano.2016.137.

(33) Alapan, Y.; Yasa, O.; Schauer, O.; Giltinan, J.; Tabak, A. F.; Sourjik, V.; Sitti, M. Soft Erythrocyte-Based Bacterial Microswimmers for Cargo Delivery. Sci. Robot. 2018, 3 (17), eaar4423. https://doi.org/10.1126/scirobotics.aar4423.

(34) Stanton, M. M.; Park, B. W.; Miguel-López, A.; Ma, X.; Sitti, M.; Sánchez, S. Biohybrid Microtube Swimmers Driven by Single Captured Bacteria. Small 2017, 13 (19), 1-10. https://doi.org/10.1002/smll.201603679.

(35) Matsumoto, Y.; Chen, R.; Anikeeva, P.; Jasanoff, A. Engineering Intracellular Biomineralization and Biosensing by a Magnetic Protein. Nat. Commun. 2015, 6. https://doi.org/10.1038/ncomms9721.

(36) Nishida, K.; Silver, P. A. Induction of Biogenic Magnetization and Redox Control by a Component of the Target of Rapamycin Complex 1 Signaling Pathway. PLoS Biol. 2012, 
10 (2). https://doi.org/10.1371/journal.pbio.1001269.

(37) Lee, J.-H.; Roh, Y.; Hur, H.-G. Microbial Production and Characterization of Superparamagnetic Magnetite Nanoparticles by Shewanella Sp. HN-41. J. Microbiol. Biotechnol. 2008, 18 (9), 1572-1577.

(38) Ramesh, P.; Hwang, S. J.; Davis, H. C.; Lee-Gosselin, A.; Bharadwaj, V.; English, M. A.; Sheng, J.; Iyer, V.; Shapiro, M. G. Ultraparamagnetic Cells Formed through Intracellular Oxidation and Chelation of Paramagnetic Iron. Angewandte Chemie - International Edition. 2018. https://doi.org/10.1002/anie.201805042.

(39) Liu, X.; Lopez, P. A.; Giessen, T. W.; Giles, M.; Way, J. C.; Silver, P. A. Engineering Genetically-Encoded Mineralization and Magnetism via Directed Evolution. Sci. Rep. 2016, 6, 1-10. https://doi.org/10.1038/srep38019.

(40) Lau, Y. H.; Giessen, T. W.; Altenburg, W. J.; Silver, P. A. Prokaryotic Nanocompartments Form Synthetic Organelles in a Eukaryote. Nat. Commun. 2018, 9 (1).

https://doi.org/10.1038/s41467-018-03768-X.

(41) Tatur, J.; Hagedoorn, P. L.; Overeijnder, M. L.; Hagen, W. R. A Highly Thermostable Ferritin from the Hyperthermophilic Archaeal Anaerobe Pyrococcus Furiosus. Extremophiles 2006, 10 (2), 139-148. https://doi.org/10.1007/s00792-005-0484-X.

(42) Isberg, R. R.; Voorhis, D. L.; Falkow, S. Identification of Invasin: A Protein That Allows Enteric Bacteria to Penetrate Cultured Mammalian Cells. Cell 1987, 50 (5), 769-778. https://doi.org/10.1016/0092-8674(87)90335-7. 


\section{Figures}

$(A, B)$ HRTEM on individual E. Coli

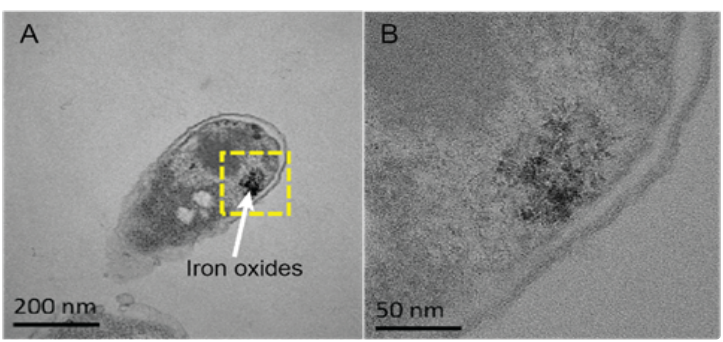

(E-H) Elemental Maps Analysis

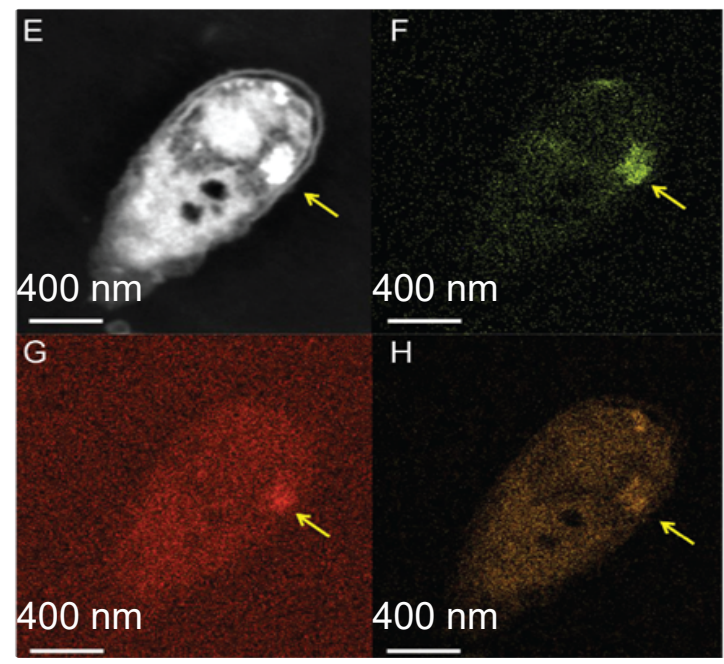

C Chemical Analysis (EDX)

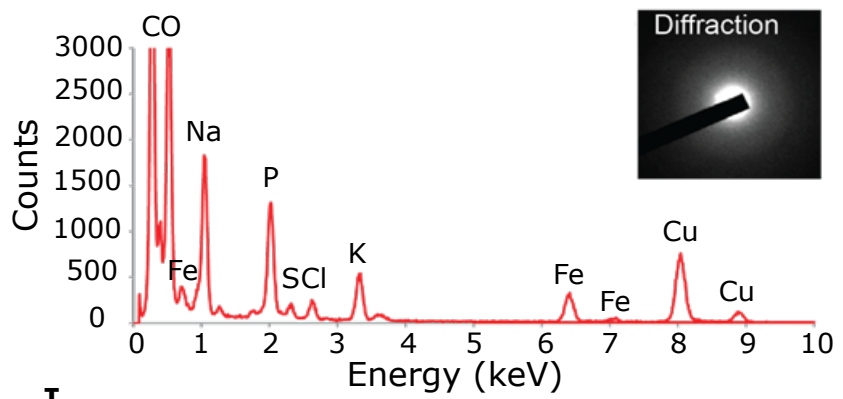

I

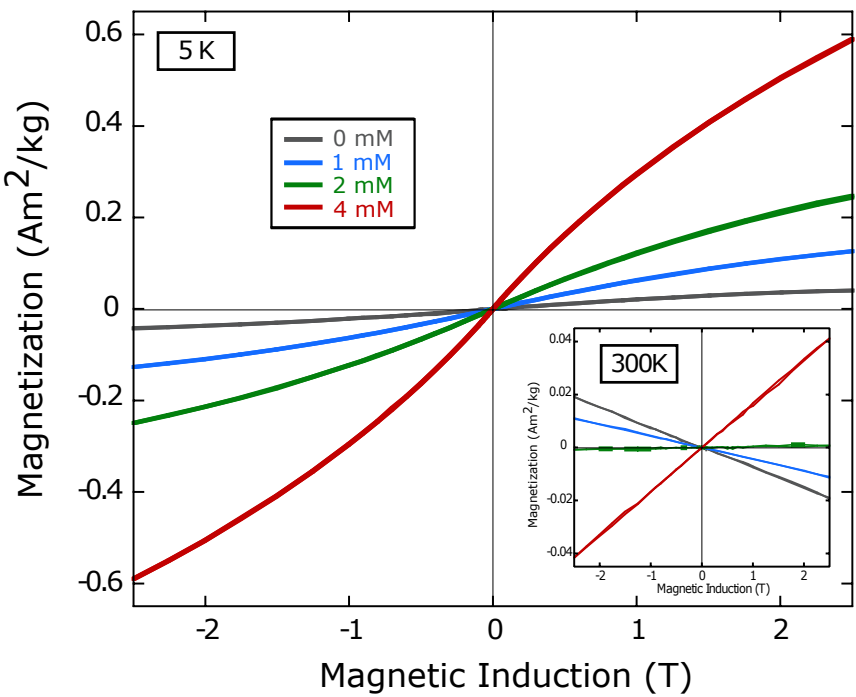

Figure 1. Structural and chemical characterization of MagEcoli bacteria. (A,B) TEM images of a cross sectioned mineralized mCherry-ferritin expressing E. coli strain. (C) Energy dispersive X-ray spectroscopy spectra of the electron - dense deposit (yellow area). (D) Electron diffraction pattern of nanoparticles. (E - H) Elemental mapping of a mineralized cross-section of mCherry-ferritin expressing $E$. coli strain. (E) STEM image. (F-H) Each panel represents the detection of a different element: Iron (F), Oxygen (G), Phosphorus (H). (I) Magnetization curves of mineralized E. coli for different concentration of iron supplementation: $0 \mathrm{mM}$ (black), $1 \mathrm{mM}$ (blue), $2 \mathrm{mM}$ (green), $4 \mathrm{mM}$ (red). Measurements were performed at $5 \mathrm{~K}$ and $300 \mathrm{~K}$ (insert) on a MPMS, with magnetic inductions cycling between $+2.5 \mathrm{~T},-2.5 \mathrm{~T}$, and $+2.5 \mathrm{~T}$. 

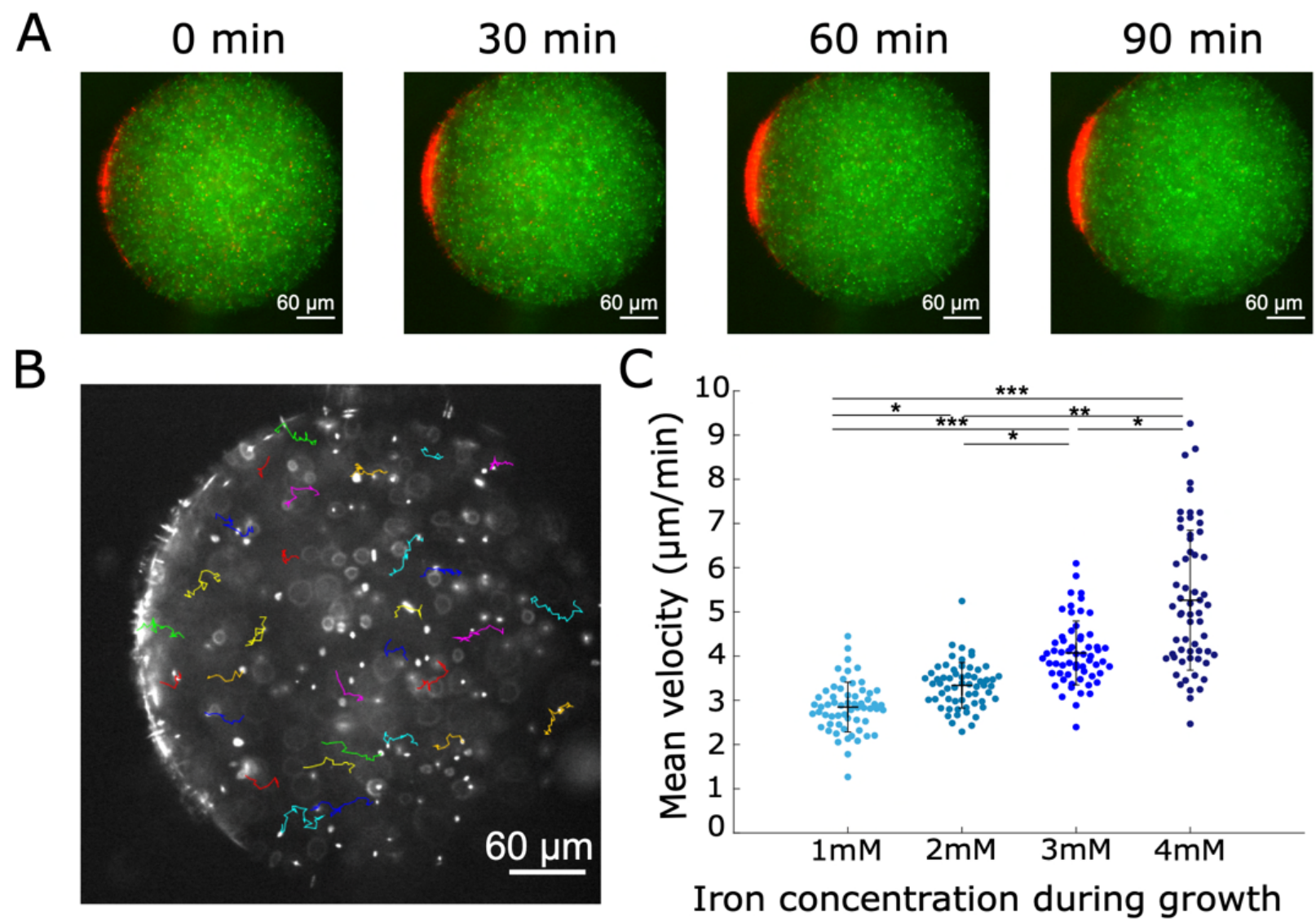

Figure 2. Biomineralized bacteria can be micromanipulated through space with a magnetic field. (A) Representative time lapse epifluorescence acquisition of the magnetic localization of MagEcoli ${ }^{\text {mCherry }}$ in a confined environment upon magnetic force application. MagEcoli ${ }^{\text {mCherry }}$ were homogenously mixed with non-magnetic E.coli ${ }^{G F P}$ at early time point. The magnet was positioned on the left. Time points at 0 , 30, 60, 90 min after starting acquisition, color merged. (B) Representation of trajectories as a function of time of MagEcoli ${ }^{\text {Cherry }}$ mineralized with $2 \mathrm{mM}$ of iron II. Magnet on the left. (C) Histogram of bacterial speed during magnetophoresis experiments as a function of iron concentration during biomineralization. For each condition, the mean $+/$ - standard deviation are displayed, for two independent experiments. NS means there is no significant difference between the two distributions, one star means $p$-value $<10^{-5}$, two stars mean $\mathrm{p}$-value $<10^{-10}$, three stars mean $\mathrm{p}$-value $<10^{-15}$. 


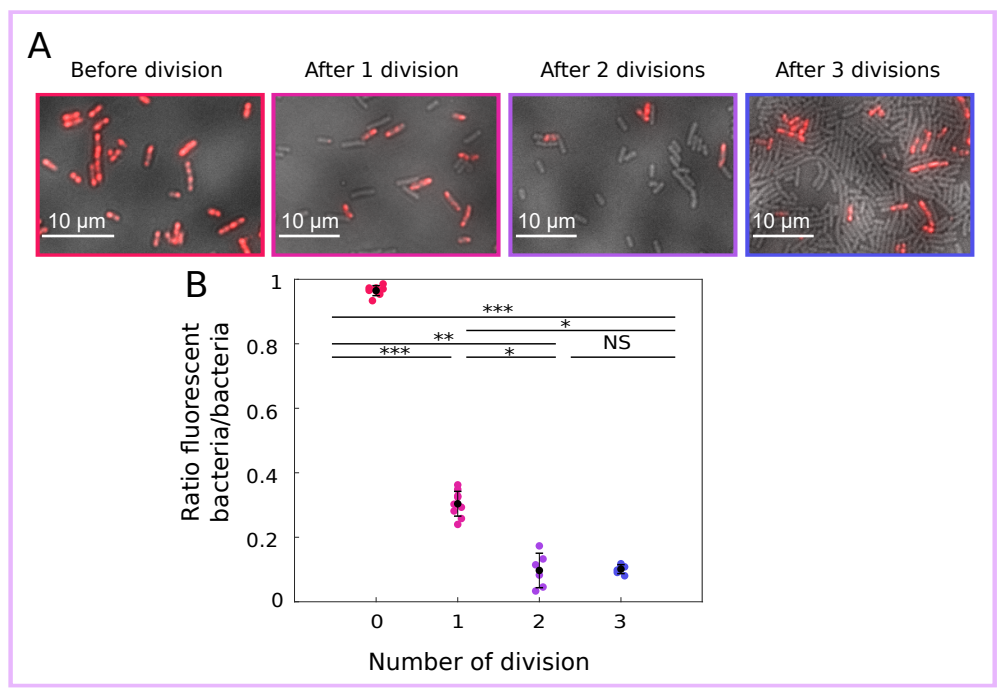

$$
\begin{aligned}
& \text { C } \\
& \text { E }
\end{aligned}
$$
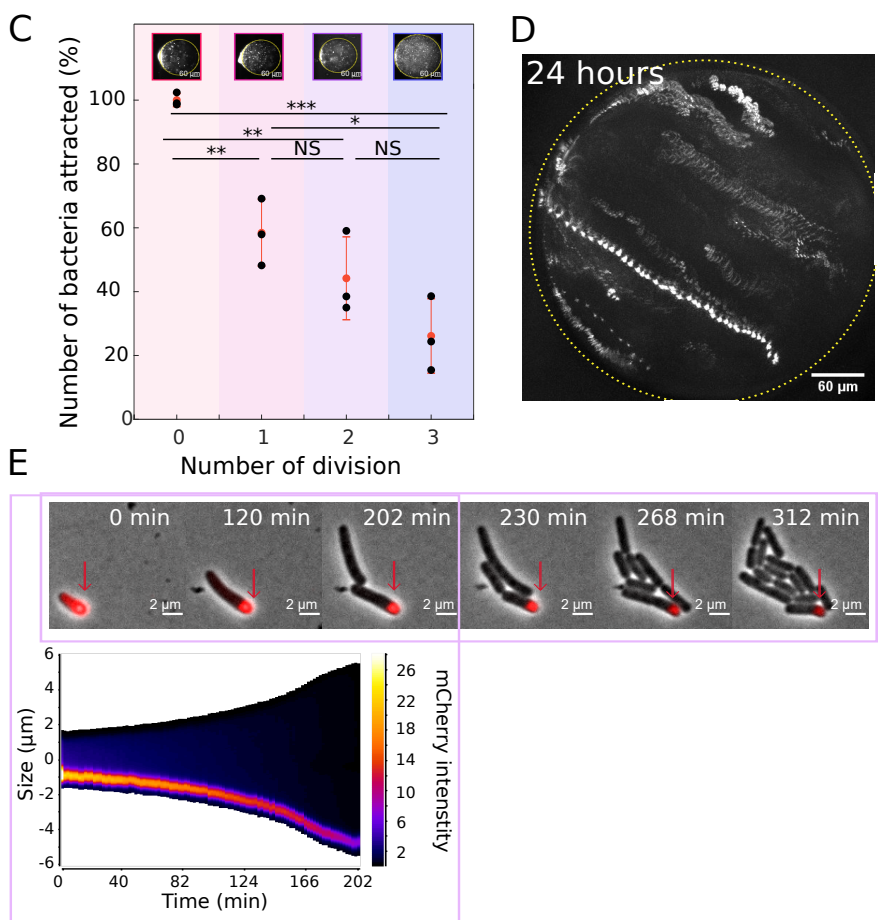

Figure 3. Evolution of the magnetic properties of MagEcoli as a function of cell division. (A) Superimposition of mCherry fluorescence and bright field images of mineralized bacteria after $0,1,2$, and 3 divisions. (B) Quantification of the evolution as a function of cell division of the ratio of bacteria remaining magnetic compared to the total number of growing bacteria (1000 bacteria, two different experiments performed at different days). Each point represents a ratio computed from a microscopic observation. The mean +/- standard deviation are displayed. NS means there is no significant difference between the two distributions, one star means p-value $<10^{-5}$, two stars mean p-value $<10^{-10}$, three stars mean p-value $<10^{-15}$. (C) Upper panel: Representative magnetophoresis images of the accumulation of MagEcoli after 0, 1, 2, and 3 divisions. Images were taken 90 min after starting the accumulation; magnet 
is on the left, scale bar, $60 \mu \mathrm{m}$. Graph: Quantification of the number of bacteria attracted towards the magnet for the corresponding experiment. For each condition, the mean $+/$ - standard deviation is displayed for three independent experiments. NS means there is no significant difference between the two distributions, one star means p-value $<0.1$, two stars mean p-value $<0.01$, three stars mean p-value $<$ 0.001. (D) Projection of bacterial trajectories integrated on 50 minutes of bacteria still containing mineralized ferritins after 24 hours of new growth. Magnet on the bottom left. (E) Time-lapse images of live fluorescence microscopy images (Merged images of phase contrast and mCherry channels, level of mCherry adjusted for each image). Time points at 0, 120, 202, 230, 268 and $312 \mathrm{~min}$. Lower panel: Kymograph of the dividing bacteria displayed on top. 

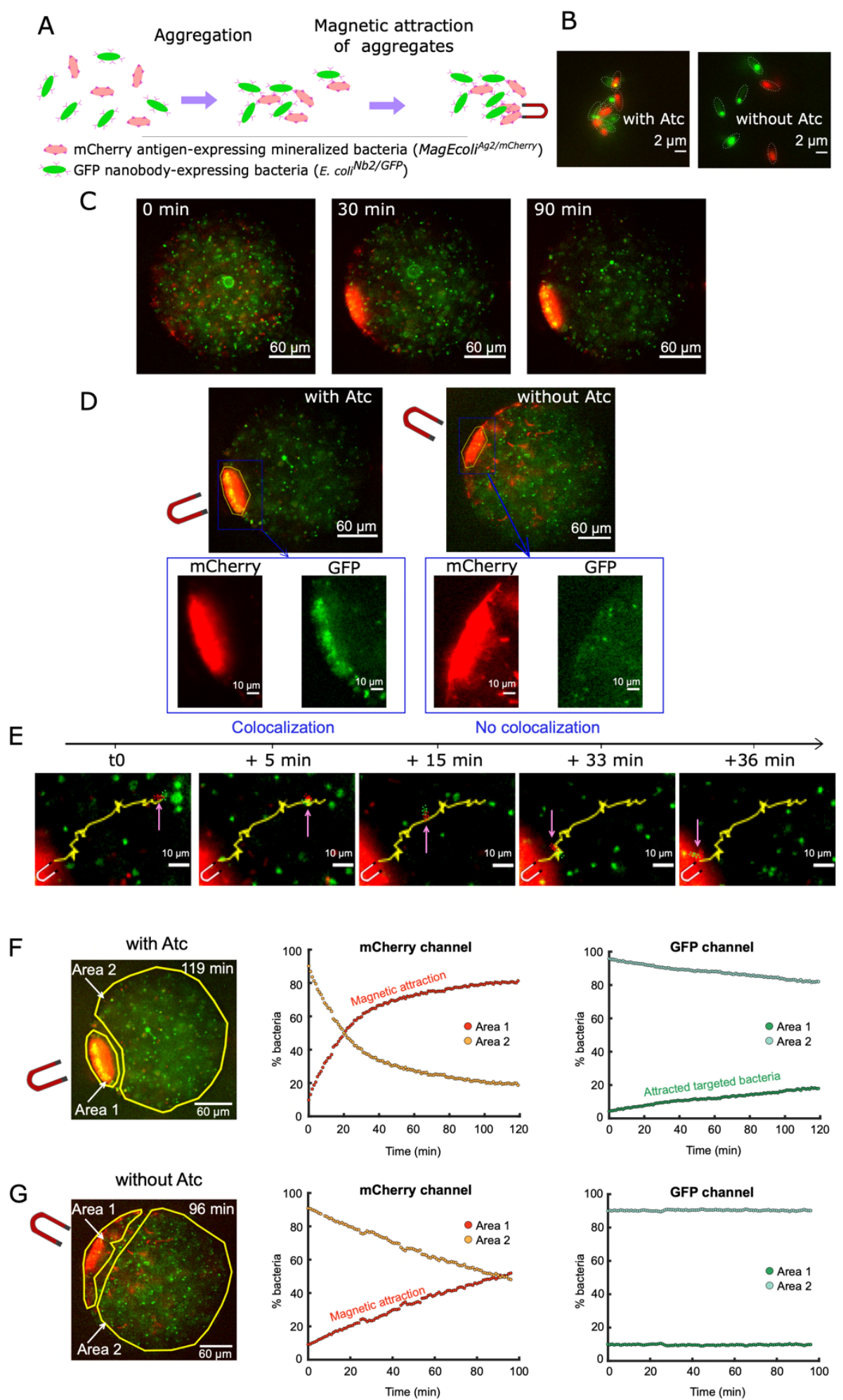

Figure 4. Capture and spatial attraction of targeted bacteria by antigen/antibody recognition. (A) Scheme of the assay of the capture and spatial attraction of targeted bacteria by antigen/antibody recognition. GFP nanobody-expressing bacteria $\left(E\right.$. coli $\left.^{N b 2 / G F P}\right)$ can adhere to mCherry antigen-expressing mineralized E. coli (MagEcoli $\left.{ }^{A g 2 / m C h e r r y}\right)$. (B) On the left panel: aggregation of antigen-presenting 
MagEcoli (mCherry) with nanobody-presenting E. coli (GFP), in presence of anhydrotetracycline (Atc). On the right panel: control performed without anhydrotetracycline. Epifluorescence observations. Merged images. Scale bar, $2 \mu \mathrm{m}$. (C) Time lapse images of magnetic accumulation of antigen-producing MagEcoli (mCherry) adhering to nanobody-producing E. coli (GFP). Images at $0 \mathrm{~min}, 30 \mathrm{~min}$ and $90 \mathrm{~min}$ upon magnetic field application. Merged images. Scale bar, $60 \mu \mathrm{m}$. (D) Images of magnetic accumulation of aggregates in the presence (left) or in the absence (right) of anhydrotetracycline. Merged images. Scale bar $60 \mu \mathrm{m}$. Below: zoom of the accumulation of magnetic bacteria. Colorized images. Extracted from the movie in panel C. Scale bar, $10 \mu \mathrm{m}$. (E) Time-lapse images showing the trajectory two adhering bacteria (MagEcoli ${ }^{A g 2 / m C h e r r y}$ and E. coli ${ }^{N b 2 / G F P}$ ) over time. Extracted from the movie in panels C and D. Merged images. Scale bar, $10 \mu \mathrm{m}$. (F) Quantification of the number of bacteria attracted in presence of anhydrotetracycline using the data extracted from the time-lapse of the panel D (left). Left panel: The two regions of interest used for the quantification are highlighted in yellow. Merged channel. Middle panel: plot of the intensity of fluorescence of MagEcoli ${ }^{A g 2 / m C h e r r y}$ next to the magnet (area 1, red) and far from the magnet (area 2, orange), as a function of time. Right panel: plot of the intensity of fluorescence of $E$. $\operatorname{coli}^{\text {Nb2/GFP }}$ next to the magnet (area 1, dark green) and far from the magnet (area 2, light green), as a function of time. (G) Quantification of the number of bacteria attracted in absence of anhydrotetracycline using the data extracted from the time-lapse of panel D (Right). Left panel: The two regions of interest used for the quantification are highlighted in yellow. Merged channel. Middle panel: plot of the intensity of fluorescence of MagEcoli ${ }^{A g 2 / m C h e r r y}$ next to the magnet (area 1, red) and far from the magnet (area 2, orange), as a function of time. Right panel: plot of the intensity of fluorescence of $E$. $\operatorname{coli}^{\mathrm{Nb2} / G F P}$ next to the magnet (area 1, dark green) and far from the magnet (area 2, light green), as a function of time. 


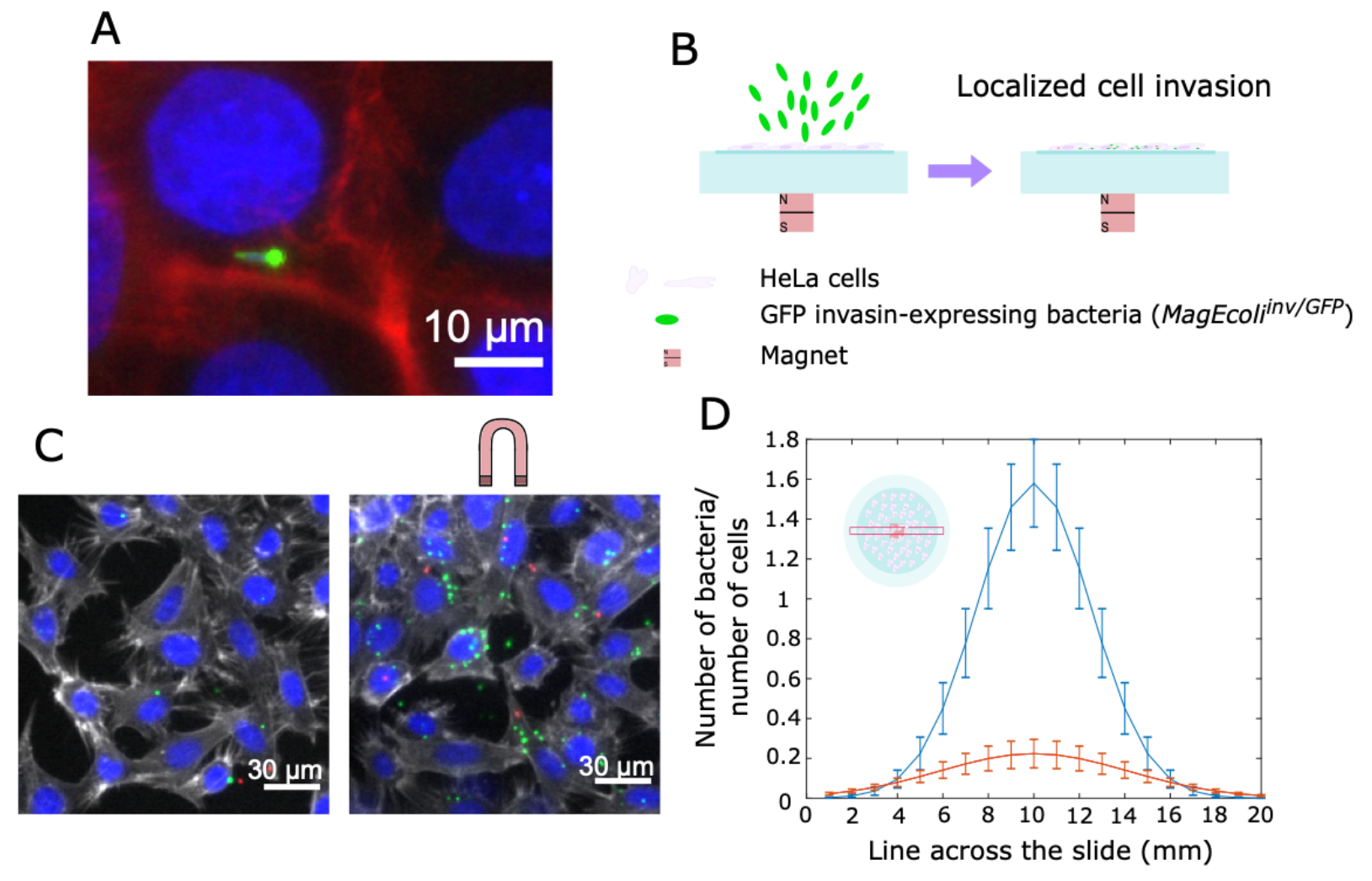

Figure 5. Magnetic localization of bacterial infection of HeLa cells. (A) Epifluorescence images of MagEcoli ${ }^{i n v / G F P}$ inside a Lovo cell. In blue, nucleus of human cells (LoVo) and bacterial DNA; in red, actin; in green, ferritin of MagEcoli ${ }^{i n / G F P}$. (B) Scheme of the set-up used to localize invasion of HeLa Cells by magnetic invasive bacteria. MagEcoli ${ }^{\text {inv/GFP }}$ are placed on a culture dish covered with Hela Cells. (C) Epifluorescence images of invasion of Hela cells by MagEcolinv/GFP. In blue, nucleus of HeLa cells; in gray, actin; in green, MagEcolinv/GFP ; in red, E. coli ${ }^{\text {inv/mCherry }}$. (D) Number of bacteria that invaded one HeLa Cell. In blue, the mean of the number of MagEcoli $i^{i n v / G F P}$ for 4 different zones of observation on the same sample; in red, the respective number of E. colinv/mCherry. The x-axis represents the zone of observation, in $\mathrm{mm}$. Data are normalized by the number of nucleus of cells counted on each field of observation, and a Gaussian fit was applied on the data for each zone of observation. 